\title{
QUASI-STEADY STATE THERMAL PERFORMANCES OF A SOLAR AIR HEATER WITH TWO ABSORBER
}

\author{
A. O. DISSA, H. DESMORIEUX AND J. KOULIDIATI
}

(Received 16 July 2016; Revision Accepted 5 August 2016)

\begin{abstract}
Quasi-steady state thermal performance of a solar air heater with a combined absorber is studied. The whole energy balance equations related to the system were articulated as a linear system of temperature equations. Solutions to this linear system were assessed from program based on an iterative process. The mean temperature variation with time and the thermal performance parameters were deduced from simulation outputs. Simulations were performed for typical days of the twelve months of the year. Results show maximum values of mean temperatures at solar noon ranging between: $78^{\circ} \mathrm{C}$ and $87^{\circ} \mathrm{C}$ for the cover, $102^{\circ} \mathrm{C}$ and $114{ }^{\circ} \mathrm{C}$ for the absorber $61^{\circ} \mathrm{C}$ to $67^{\circ} \mathrm{C}$. Experimental and simulated results correlate well for hours before solar noon (with $\mathrm{R}^{2} \approx 0.988$ ) and show some discrepancies for hours after solar noon. These differences were related to the neglect of heat capacity effects in the model. Experimental and calculated solar heater efficiencies at solar noon approached respectively about 62 and $61 \%$. The removal factor FR and the efficiency factor F' calculated were respectively 0.4 and 0.33 , whereas the values assessed from experiments were respectively 0.79 and 0.63 . This model allowed predicting the collector performances and is more suitable for hours before solar noon.
\end{abstract}

KEYWORDS: Quasi-steady state, solar air heater, combined absorber, modeling, experiment

\section{INTRODUCTION}

For low temperature solar heating applications two kind of solar air heaters are commonly used relates to the type of absorber: porous absorber collectors and non-porous absorber collectors. Porous absorbers air heaters with high heat transfer coefficients have usually the best performances [1], but they operate at very low temperatures. Non-porous absorbers air heaters operate at very high temperatures but have very low heat transfer rate because of small exchange surfaces between the plates and fluid. To improve performances of solar air heaters, several authors were interested in both types of the system. Ong [2] established a mathematical model with solution procedure to predict the thermal performance for four kinds of solar air heaters. Mohamad [3] found that a higher efficiency solar air heater (with thermal efficiency ranging from 25 to $80 \%$ ) can be obtained by a system combining double air passage and a high porous absorber. Ekechukwu \& Norton [4] carried out a review of various designs and performance evaluation technique of low temperature air-heating solar collectors for crop drying applications. These authors also highlighted the appropriateness of each design of solar heater and the choice of materials to operate for each component. Koyuncu [5] studied the performances of six different types of natural convection solar air heater. He found that unlike number of glazing sheet and air pass method, the effect of the shape of the absorbing surface on the performance is considerably less. Aboul-Enein and al. [6] carried out a parametric study of solar air heater with and without thermal storage for solar drying applications. These authors investigated the effects of design parameters of the air heater such as length, width, gap spacing between the absorber plate and glass cover, mass flow rate and type of the storage material (sand, granite and water) on the outlet and average temperatures of the flowing air. AbuHamdeh [7] developed a mathematical model for predicting thermal efficiency, heat gain, and outlet air temperature of a covered plate attic solar collector under steady conditions. While performing simulations, he explored the influence of the air speed inside the collector and wind speed above the collector on the collector efficiency.

In order to improve the thermal performances of the solar air heater, we suggest a new type of this system with a composite absorber combining a porous absorber made of a porous metallic medium and a nonporous absorber made of a non-porous metallic plate placed above. The advantages of this coupling comes from the fact that: (i) the specific heat transfer surface is high because the air crosses the porous absorber and (ii) the absorber is kept at a high mean temperature thanks to the non-porous metallic plate. The current study on this kind of solar air heater presents a more

A. O. Dissa, Laboratoire de Physique et de Chimie de l'Environnement (LPCE), Unité de Formation et de Recherche en Sciences Exactes et Appliquée (UFR/SEA), Université de Ouagadougou, BP7021, Burkina Faso.

H. Desmorieux, Laboratoire d'Automatisme et de Génie des Procédés (LAGEP), UCBL1-CNRS UMR 5007-CPE Lyon, Bât.308G,43 bd du 11 Nov.1918 Villeurbanne, Université Claude Bernard Lyon1, Lyon, France.

J. Koulidiati, Laboratoire de Physique et de Chimie de l'Environnement (LPCE), Unité de Formation et de Recherche en Sciences Exactes et Appliquée (UFR/SEA), Université de Ouagadougou, BP7021, Burkina Faso. 
detailed analysis on the quasi-steady state performance parameters such as overall heat loss coefficient UL, removal factor FR and efficiency factor coefficient $F^{\prime}$ of this kind of solar air heater. In the study, mean temperatures and thermal performances of the solar air heater are modelled in quasi-steady state and compared to experimental data.

\begin{tabular}{|c|c|}
\hline \multicolumn{2}{|c|}{ Nomenclature } \\
\hline$A, B$ & coefficients of the sky state \\
\hline a & surface area volume ratio, $\left(m^{-1}\right)$ \\
\hline C & $\begin{array}{l}\text { solar radiation correction factor due to earth-sun } \\
\text { distance variation }\end{array}$ \\
\hline$C_{n m}$ & $\begin{array}{l}\text { coefficient of coupling conductive heat transfer } \\
\text { between elements } n \text { and } m\end{array}$ \\
\hline $\begin{array}{l}C_{p} \\
d_{a}\end{array}$ & $\begin{array}{l}\text { heat capacity }\left(\mathrm{J} \mathrm{kg}^{-1} \mathrm{~K}^{1}\right) \\
\text { diameter of the aluminum wire of the porous } \\
\text { absorber mesh }\left(\mathrm{d}_{\approx} \approx 0.45 \mathrm{~mm}\right)\end{array}$ \\
\hline$D_{h}$ & equivalent hydraulic diameter of the useful duct \\
\hline
\end{tabular}

$(m)$

$F^{\prime} \quad$ efficiency factor

$F^{\prime \prime} \quad$ flow factor

$F_{\mathrm{R}} \quad$ removal factor

$G_{0} \quad$ Incident solar radiation $\left(W m^{-2}\right)$

$G_{O D} \quad$ incident direct solar radiation $\left(W \mathrm{~m}^{-2}\right)$

$G_{0 d} \quad$ incident diffuse solar radiation $\left(W m^{-2}\right)$

$h \quad$ heat transfer coefficient $\left(W m^{-2} K^{1}\right)$

$h_{s} \quad$ sun altitude (degrees)

$i \quad$ angle between solar rays and normal direction of collecting surface (degrees)

$I_{0} \quad$ solar constant $\left(I_{0}=1353 \mathrm{~W} \mathrm{~m}^{-2}\right)$

$L \quad$ length of the collector $(m)$

$\dot{m} \quad$ air flow rate through collector $\left(\mathrm{kg} \mathrm{s}^{-1}\right)$

$n_{0} \quad$ number of the month in the year

$n_{1} \quad$ number of the day in the month

$\mathrm{Nu} \quad$ Nusselt number

$p \quad$ atmospheric pressure $\left(p=1.015 \times 10^{5} \mathrm{~Pa}\right)$

$P_{n} \quad$ heat source in the element $\mathrm{n}\left(W \mathrm{~m}^{-2}\right)$

$\mathrm{Pr} \quad$ Prandtl number

$Q u \quad$ useful power transferred to the airstream in the useful duct, $W$

Ra Raleigh number

Re Reynolds Number

$R_{n m} \quad$ coefficient of coupling radiative heat transfer between elements $n$ and $m$

$S \quad$ useful duct cross-sectional area $\left(\mathrm{m}^{2}\right)$

$t \quad$ operating time of the collector $(t)$

$T$ temperature $(K)$

$\bar{T}_{a} \quad$ average ambient temperature $(K)$

$U L \quad$ overall heat loss coefficient $\left(W m^{-2} K^{1}\right)$

$u_{b} \quad$ bottom heat loss coefficient $\left(W m^{-2} K^{1}\right)$

$u_{s} \quad$ sides heat loss coefficient $\left(W m^{-2} K^{1}\right)$

$u_{t} \quad$ top heat loss coefficient $\left(W m^{-2} K^{1}\right)$

$V_{n m} \quad$ coefficient of coupling convective heat transfer between elements $n$ and $m$

$v \quad$ air velocity $\left(m s^{-1}\right)$

W width of the collector $(m)$

$x \quad$ coordinate in air flow direction $(m)$

$y \quad$ thickness of insulation, $(m)$

\section{Greek letters}

$\alpha \quad$ solar azimuth angle (degrees)

$\alpha_{1} \quad$ absorptivity of the cover

$\alpha_{2} \quad$ absorptivity of the absorber sheet $\beta \quad$ tilt angle of collector surface (degrees)

$\delta \quad$ solar declination angle (degrees)

$\varepsilon \quad$ emissivitty

$\phi \quad$ latitude (degrees)

$\lambda$ thermal conductivity $\left(W K^{-1} m^{-1}\right)$

$\eta \quad$ solar air heater efficiency

$\eta_{l}$ solar air heater energy conversion factor, $\eta_{1}=F^{\prime}\left(\tau_{1} \alpha_{2}\right)$

$\rho \quad$ density $\left(\mathrm{kg} \mathrm{m}^{-3}\right)$

$\rho_{2} \quad$ reflectivity of the absorber

$\rho_{d} \quad$ hemispherical reflectivity of the cover

$\sigma \quad$ Stefan-Boltzmann constant $\left(\sigma=5.676 \times 10^{-8} \mathrm{~W} \mathrm{~m}^{-2} \mathrm{~K}^{-4}\right)$

$\tau_{1} \quad$ cover transmittivity of the radiation

$\tau_{d} \quad$ cover transmittivity of diffuse radiation

$\checkmark$ angle between local meridian and the normal to the collector surface (degrees)

$\omega_{s} \quad$ sunrise hour angle (degrees)

\section{Subscript}

1 cover

12,21 transfer between cover and absorber

1s transfer between the sky and the cover

2 absorber

$2 \mathrm{f}, \mathrm{f} 2$ transfer between the absorber and the airstream

3 bottom insulation internal wall

$3 f$, 33 transfer between the bottom insulation and the airstream

3s, s3 transfer between the bottom insulation and porous absorber

a ambient air

C conduction

D direct radiation

d diffuse radiation

f airstream

h horizontal plane

i initial or inlet

$\mathrm{n} \quad$ element $\mathrm{n}$ of the solar air heater

$\mathrm{nm} \quad$ coupling of elements $\mathrm{n}$ and $\mathrm{m}$

o outlet

$r \quad$ radiation

s sky

sf, fs transfer between the porous absorber and the airstream

w wind

\section{MATERIALS AND METHODS}

\subsection{The experimental solar air heater}

The solar air heater with combined absorbers used in this study is schematized in Fig. 1 and its characteristics are presented on Table 1. This air heater is made of: (1) a transparent cover glass of $5 \mathrm{~mm}$ thick, (2) a composite absorber made of a non-porous absorber (a blackened vee-corrugated iron sheet of 0.27 $\mathrm{mm}$ thick) and a porous absorber (a mesh of aluminium of 0.9 porosity with a parallelepiped shape), (3) a static air layer between the cover glass and the iron sheet of $3.5 \mathrm{~cm}$ thick, (4) a rectangular duct of $85 \mathrm{~cm} \times 5 \mathrm{~cm}$ of section containing the porous absorber, (5) a bottom insulation made of layers of glass wool and shavings of $5 \mathrm{~cm}$ each, (6) an adiabatic envelope of protection made of wood.

A fraction of the incident solar radiation G0 falling on the collector is transmitted through the glazing. 
After multiple reflections of long wave-length rays toward the cover glass, the iron sheet absorbs the fraction $G_{0}\left(\tau_{1} \alpha_{2}\right)$ of the incident solar radiation. Under the iron sheet, the energy absorbed is transferred by conduction to the porous absorber matrix and the heater bottom, and by convection to the air in the duct. Moreover, the air crossing the porous matrix in the duct receives, by convection, a fraction of the energy through the porous absorber and the iron sheet.

\subsection{Measurements and data processing}

The experimental setup consisted of a system of temperature sensors connected to the different parts of the air heater. Temperatures measurement were performed at intervals of time of $5 \mathrm{mn}$ between sunrise and sunset. The recordings were carried out using a case of $\mathrm{K}$ type thermocouples connected to a computer with the data acquisition software TESTPOINT (version 3.4). Furthermore, the experimental temperature curves obtained were smoothed using a macro-program designed under Microsoft Excel. This macro fits data series with an appropriate polynomial function and replaced each value of the series by an average value in such a way to minimize the standard deviations from initial values.

\section{Theoretical approach on establishment of heat balance equations}

\subsection{Hypothesis}

The following assumptions were made:

The solar heater operates under steady-state conditions

Transfers in the useful duct are uni-directional in the direction of air flow

Each element of the solar air heater is considered to be at a uniform temperature

Thermal parameters are homogeneous in each section of the solar air heater perpendicular to the air flow.
Physical properties of materials used are independent of temperature (Table 1).

Ambient temperature is the same at the top and the bottom of the collector.

Sky and cover are assimilated respectively to black and gray bodies.

Effects of dust and dirt on the glass cover are negligible.

There is thermal balance between porous and non-porous parts of the absorber

Non-Darcian effects of flow inertia and thermal dispersion are considered.

Porous absorber is homogeneous, isotropic with a constant porosity (Table 1).

There is no penetration of solar radiation in the porous absorber i.e. solar rays are entirely stopped by the non-porous absorber plate.

Pressure losses and viscosity effects in the porous absorber are negligible

Velocity and absolute humidity of the air remain constant along the collector.

The radiative exchanges between the absorber plate and the bottom insulator are negligible because these parts of the collector are separated by the porous absorber.

\subsection{System of equations}

The solar heater is modelled by using average values of physical parameters related to the different components of the system. Fundamental variables of the model are then the temperature of the cover $\left(T_{1}\right)$, the temperature the absorber $\left(T_{2}\right)$, the mean temperature of the airstream $\left(T_{f}\right)$ and the temperature of the Bottom insulation internal wall $\left(T_{3}\right)$. These variables depend on fixed variables which are the $\mathrm{x}$-coordinate in the direction of the air flow along the useful duct of the collector $(x)$ and the operating time of the collector $(t)$. 


\subsubsection{Energy balance equations}

Energy balance equations were established by using the electric analogy relative to a vertical section of the solar heater (Figs.1a\&b). This method represents each element of the solar heater by a node placed in its center. Considering an element of surface dS of the solar air heater, the general form of the energy balance for every element can be stated as follows:

$m_{n} C p_{n} \frac{\partial T_{n}}{\partial t}=\sum_{n} d S_{n m}\left[P_{n}+\left(C_{n m}+V_{n m}+R_{n m}\right)\left(T_{m}-T_{n}\right)\right]$

where $C_{n m}, V_{n m}, R_{n m}$ are respectively the coefficient of coupling conductive, convective and radiative heat transfer between the elements $n$ and $m$; and $P_{n}$ the heat source term inside the element $\mathrm{n}$.

Considering the surface-volume ratio a relative to each element, this general form can be modified according to the following expression:

$\rho_{n} C p_{n} \frac{\partial T_{n}}{\partial t}=\sum_{n} a_{n m}\left[P_{n}+\left(C_{n m}+V_{n m}+R_{n m}\right)\left(T_{m}-T_{n}\right)\right]$

As the study is carried out in steady state, the first term of Eq. 2 is negligible. Therefore, the energy balance for every element is written:

$$
\sum_{n} a_{n m}\left[P_{n}+\left(C_{n m}+V_{n m}+R_{n m}\right)\left(T_{m}-T_{n}\right)\right]=0
$$

Heat balance equations obtained from the nodes of the thermal network of Fig. $1 \mathrm{~b}$ are then:

Energy balance on the cover

$G_{0} \alpha_{1} a_{1}\left(1+\rho_{2} \tau_{1}\right)+h_{w} a_{1}\left(T_{a}-T_{1}\right)+h_{r l s} a_{1}\left(T_{s}-T_{1}\right)+$

$\left(h_{12}+h_{r 12}\right) a_{1}\left(T_{2}-T_{1}\right)=0$

Energy balance on non-porous absorber

$G_{0}\left(\tau_{1} \alpha_{2}\right) a_{2}+\left(h_{12}+h_{r 12}\right) a_{2}\left(T_{1}-T_{2}\right)+$

$h_{2 f} a_{2 f}\left(T_{f}-T_{2}\right)=0$

Energy balance on porous absorber

$h_{s f} a_{s f}\left(T_{f}-T_{2}\right)+h_{c 3 s} a_{3 s}\left(T_{3}-T_{2}\right)=0$

Energy balance on the airstream

$\left(h_{s f} a_{s f}+h_{2 f} a_{2 f}\right)\left(T_{2}-T_{f}\right)+h_{3 f} a_{3 f}\left(T_{3}-T_{f}\right)$

$=\rho_{f} c_{p f}\left(T_{f}-T_{i}\right)$

Energy balance on the internal wall of bottom insulation

$h_{3 f} a_{3 f}\left(T_{f}-T_{3}\right)+h_{c 3 s} a_{3 s}\left(T_{2}-T_{3}\right)+u_{b} a_{3}\left(T_{a}-T_{3}\right)=0$

\subsubsection{Temperatures matrix}

Porous and non-porous absorbers are assumed to be at the same temperature. So, our system has four nodes representing cover, absorber, fluid and insulation. Combining Eq. (5) and (6) for absorber, the whole energy balance equations (4-8) gives the following system of equations leading to the temperatures matrix:

For the cover

$\left(h_{w}+h_{r 1 s}+h_{12}+h_{r 12}\right) a_{1} T_{1}-\left(h_{12}+h_{r 12}\right) a_{1} T_{2}$

$=G_{0} \alpha_{1} a_{1}\left(1+\rho_{2} \tau_{1}\right)+h_{w} a_{1} T_{a}+h_{r 1 s} a_{1} T_{s}$

For the absorber

$\left(h_{12}+h_{r 12}\right) a_{2} T_{1}-\left[h_{12} a_{2}+h_{r 12} a_{2}+h_{2 f} a_{2 f}+h_{s f} a_{s f+} h_{c 3 s} a_{3 s}\right] T_{2}+$

$\left(h_{2 f} a_{2 f}+h_{s f} a_{s f}\right) T_{f}+h_{c 3 s} a_{3 s} T_{3}=-G_{0}\left(\tau_{1} \alpha_{2}\right) a_{2}$

For the airstream

$\left(h_{2 f} a_{2 f}+h_{s f} a_{s f}\right) T_{2}-\left(h_{2 f} a_{2 f}+h_{s f} a_{s f}+h_{3 f} a_{3 f}+\rho_{f} c_{p f}\right) T_{f}+$

$h_{3 f} a_{3 f} T_{3}=-\rho_{f} c_{p f} T_{i}$

For the bottom insulation

$h_{c 3 s} a_{3 s} T_{2}+h_{3 f} a_{3 f} T_{f}-\left(h_{c 3 s} a_{3 s}+h_{3 f} a_{3 f}+u_{b} a_{3}\right) T_{3}$

$=-u_{b} a_{3} T_{a}$

The whole of equations (9-12) constitutes a system of four equations with four unknowns $T_{1}, T_{2}, T_{f}$ and $T_{3}$. This system of equations can be represented by a matrix equation $\mathrm{AT}=\mathrm{B}$ as follow:

$\left[\begin{array}{cccc}H_{1} & -H_{12}^{\prime} & 0 & 0 \\ H_{12} & -H_{2} & H_{2 f} & H_{3 c} \\ 0 & H_{2 f} & -H_{f} & H_{3 f} \\ 0 & H_{3 c} & H_{3 f} & -H_{3}\end{array}\right] \times\left[\begin{array}{c}T_{1} \\ T_{2} \\ T_{f} \\ T_{3}\end{array}\right]=\left[\begin{array}{c}K_{1} \\ K_{2} \\ K_{3} \\ K_{4}\end{array}\right]$

The solution to this matrix equation $\mathrm{AT}=\mathrm{B}$ is a temperature vector $\mathrm{T}=\mathrm{BA}{ }^{-1}$ giving the mean temperatures according to the following expressions: 
$T_{1}=\frac{H_{12}}{H_{1}}\left[\begin{array}{l}\frac{B_{1}}{A_{1} B_{0}-B_{1} A_{0}}\left(\frac{H_{12}}{H_{1} H_{3 c}} K_{1}-\frac{1}{H_{3 c}} K_{2}+\frac{1}{H_{3 f}} K_{3}\right)+B_{1} A_{0} \\ \frac{1}{B_{0}}\left(\frac{1}{H_{3 f}} K_{3}+\frac{1}{H_{3}} K_{4}\right)\end{array}\right]+\frac{1}{H_{1}} K_{1}$

$T_{2}=\frac{B_{1}}{A_{1} B_{0}-B_{1} A_{0}}\left(\frac{H_{12}}{H_{1} H_{3 c}} K_{1}-\frac{1}{H_{3 c}} K_{2}+\frac{1}{H_{3 f}} K_{3}\right)$

$+\frac{1+B_{1} A_{0}}{B_{0}}\left(\frac{1}{H_{3 f}} K_{3}+\frac{1}{H_{3}} K_{4}\right)$

$T_{f}=\frac{-1}{A_{1} B_{0}-B_{1} A_{0}}\left[\begin{array}{l}B_{0}\left(\frac{H_{12}}{H_{1} H_{3 c}} K_{1}-\frac{1}{H_{3 c}} K_{2}+\frac{1}{H_{3 f}} K_{3}\right) \\ +A_{0}\left(\frac{1}{H_{3 f}} K_{3}+\frac{1}{H_{3}} K_{4}\right)\end{array}\right]$

$T_{3}=\frac{H_{f} B_{0}+H_{2 f} B_{1}}{H_{3 f}\left(A_{1} B_{0}-B_{1} A_{0}\right)}\left(-\frac{H_{12}}{H_{1} H_{3 c}} K_{1}+\frac{1}{H_{3 c}} K_{2}-\frac{1}{H_{3 f}} K_{3}\right)$

$-\frac{1}{H_{3 f}}\left(\frac{H_{f} A_{0}}{A_{1} B_{0}-B_{1} A_{0}}+\frac{H_{2 f}+H_{2 f} B_{1} A_{0}}{B_{0}}\right)\left(\frac{1}{H_{3 f}} K_{3}+\frac{1}{H_{3}} K_{4}\right)+\frac{1}{H_{3 f}} K_{3}$

With : $K_{1}=G_{0} \alpha_{1} a_{1}\left(1+\rho_{2} \tau_{1}\right)+h_{w} T_{a}+h_{r 1 s} T_{s}$,

$K_{2}=-G_{0}\left(\tau_{1} \alpha_{2}\right) a_{2}, K_{3}=-\rho_{f} c_{p f} T_{i}$,

$K_{4}=-u_{b} a_{3} T_{a}$

$H_{1}=h_{w}+h_{r 1 s}+h_{12}+h_{r 12}, H_{12}^{\prime}=\left(h_{12}+h_{r 12}\right) a_{1}, H_{12}=\left(h_{12}+h_{r 12}\right) a_{2}, H_{2 f}=h_{2 f} a_{2 f}+h_{s f} a_{s f} H_{2}=h_{12} a_{2}+h_{r 12} a_{2}+h_{2 f} a_{2 f}+h_{s f} a_{s f}+h_{c 3 s} a_{3 s}$,

$H_{c 3}=h_{c 3 s} a_{3 s}, H_{2 f}=h_{2 f} a_{2 f}+h_{s f} a_{s f}, H_{f}=h_{2 f} a_{2 f}+h_{s f} a_{s f}+h_{3 f} a_{3 f}+\rho_{f} c_{p f}, H_{3 f}=h_{3 f} a_{3 f}, H_{3}=h_{c 3 s} a_{3 s}+h_{3 f} a_{3 f}+u_{b} a_{3}$ and

$A_{0}=\frac{H_{12} H_{12}^{\prime}-H_{2} H_{1}}{H_{2} H_{1} H_{3 c}}-\frac{H_{2 f}}{H_{3 f}}, A_{1}=\frac{H_{2 f}}{H_{3 c}}+\frac{H_{f}}{H_{3 f}}, B_{0}=\frac{H_{2 f}}{H_{3 f}}+\frac{H_{3 c}}{H_{3}}, B_{1}=\frac{H_{3 f}}{H_{3}}-\frac{H_{f}}{H_{3 f}}$

Above solutions to the linear system give temperature functions whose constants (convective heat transfer coefficients, ambient temperature, solar radiation) also depend on temperatures. This requires a numerical iterative method to reach definitive solutions.

\subsection{Numerical solution procedure}

The solutions to the linear system were assessed from a simulation program generated by Matlab R2013 version software. This program was based on a calculation algorithm whose iterative process follows the flow shart in Fig.2. Mean temperatures were considered. The numerical solutions were obtained by dividing the running time $t$ of the air heater into a finite number $\mathrm{n}_{\max }$ of time steps $\Delta \mathrm{t}$ between the sunrise hour $(S R H)$ and the sunset hour (SSH). The iterative process then ran temperatures using a subroutine made of numerical equations derived from equations (14-17). The temperature values obtained after calculation were then compared to those initially-assumed. For the first time step corresponding to sunrise, the collector is assumed to be at ambient temperature. Each temperature is then set to ambient temperature. The whole heat transfer and heat loss coefficients were calculated based on this initial temperature. The iterative process then starts using a subroutine made of numerical equations derived from the matrix-inversion $T=B^{-1} A$.

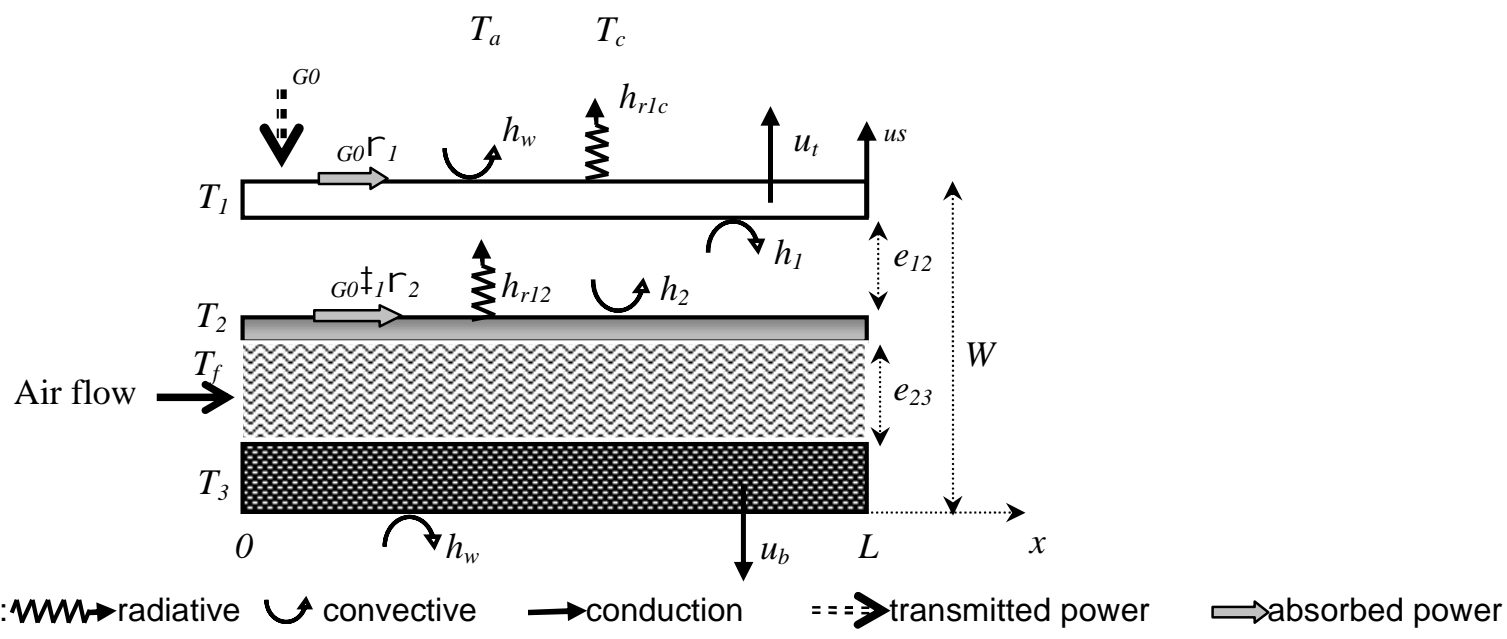

Legend: $\mathbf{W} \longrightarrow$ radiative $\cup$ convective $\rightarrow$ conduction $==$ - $\rightarrow$ transmitted power $\Rightarrow$ absorbed power

Figure 1: schematic illustration of heat transfers occurring during the solar air heater operating 
New temperature values determined are then compared with the assumed values. When the difference between them equals or is less than $0.01^{\circ} \mathrm{C}$ the calculation stops. At the end of the iterations, outlet temperature at each instant is computed from the useful heat, the mean air temperature and the inlet air temperature. The second step is then initialized with output temperature of the first step and the iteration procedure is repeated. Iterations are then executed until the last time step corresponding to the sunset hour. At the end, the program stored the mean temperatures of the different parts of the solar air heater, the air outlet temperature and the thermal efficiency.

\subsection{Estimation of model basic parameters}

\subsubsection{Solar radiation}

The solar radiation rising on the air heater collecting surface with a tilt angle $\beta$ was estimated using the following formula:

$$
G_{0}=I_{0} C A \exp \left(-\frac{B p}{1000 \sinh _{s}}\right) \cos i+\frac{1}{2}\left[\begin{array}{l}
G_{0 d h}(1+\cos \beta)+ \\
A_{0}\left(G_{0 D h}+G_{0 d h}\right)(1-\cos \beta)
\end{array}\right]
$$

Where $I_{0}$ is the solar constant $\left(I_{0}=1353 \mathrm{~W} / \mathrm{m}^{2}\right), \quad p$ the atmospheric pressure, $A_{0}$ the albedo, $A$ and $B$ the characteristic coefficients of the sky state and $\beta$ the tilt angle of the air heater $(d e g)$.

$C$ (the solar radiation correction factor due to earth-sun distance variation), $h_{s}$ (the sun altitude expressed in degrees) and $i$ (the angle between solar rays and the normal direction of the collecting surface) are given by:

$\left\{\begin{array}{l}C \approx 1+0.034 \cos \left[30\left(n_{0}-1\right)+n_{1}\right] \\ \sinh { }_{s}=\sin \phi \sin \delta+\cos \delta \cos \phi \cos \omega_{s} \\ \cos i=\sin \beta \cosh { }_{s} \cos (\alpha-v)+\cos \beta \sinh _{s}\end{array}\right.$

$G_{O D h}$ and $G_{O d h}$ respectively the direct and diffuse radiations on an horizontal plane are stated as:

$\left\{\begin{array}{l}G_{0 d h}=I_{o} C\left[0.271-0.2939 A \exp \left(\frac{-B p}{1000 \sinh _{s}}\right)\right] \times \sinh _{s} \\ G_{0 D h}=I_{o} C A \exp \left(\frac{-B p}{1000 \sinh _{s}}\right)\end{array}\right.$

Table 1: Dimensions and thermophysical characteristics of the experimental solar air heater

\begin{tabular}{|c|c|c|}
\hline $\begin{array}{ll}\text { Solar } & \text { heater } \\
\text { components } & \end{array}$ & Geometrical and thermophysical parameters & Value \\
\hline \multirow[t]{9}{*}{ Cover glass } & Length & $2.0 \mathrm{~m}$ \\
\hline & Width & $0.93 \mathrm{~m}$ \\
\hline & Thickness & $5 \mathrm{~mm}$ \\
\hline & Distance cover glass - absorber sheet & $3.5 \mathrm{~cm}$ \\
\hline & Transmittance for diffuse radiation & 0.7617 \\
\hline & Emissivity & 0.88 \\
\hline & Absorptivity & 0.13 \\
\hline & Density & $2515 \mathrm{~kg} \mathrm{~m}^{-3}$ \\
\hline & Specific heat & $820 \mathrm{~J} \mathrm{~kg}^{-1} \mathrm{~K}^{-1}$ \\
\hline \multirow[t]{7}{*}{ Absorber plate } & Length & $2 \mathrm{~m}$ \\
\hline & Width & $0.90 \mathrm{~m}$ \\
\hline & Thickness & $0.27 \mathrm{~mm}$ \\
\hline & Emissivity (black paint) & 0.95 \\
\hline & Absorptivity (black paint) 0.975 & 0.975 \\
\hline & Density & $7880 \mathrm{~kg} \mathrm{~m}^{-3}$ \\
\hline & Specific heat & $511 \mathrm{~J} \mathrm{~kg}^{-1} \mathrm{~K}^{-1}$ \\
\hline \multirow[t]{5}{*}{ Porous absorber } & Apparent volume & $0.1116 \mathrm{~m}^{3}$ \\
\hline & Solid matrix volume & $3850 \mathrm{~cm}^{3}$ \\
\hline & Porosity & 0.96 \\
\hline & Density (aluminium) & $2675 \mathrm{~kg} \mathrm{~m}^{-3}$ \\
\hline & Specific heat & $938.3 \mathrm{~J} \mathrm{~kg}^{-1} \mathrm{~K}^{-1}$ \\
\hline \multirow[t]{3}{*}{ Useful duct } & Length & $2.02 \mathrm{~m}$ \\
\hline & Width & $0.85 \mathrm{~m}$ \\
\hline & Height & $6.5 \mathrm{~cm}$ \\
\hline \multirow{2}{*}{$\begin{array}{l}\text { Airstream and ambient } \\
\text { air }\end{array}$} & Density: $\quad \rho=1.1774-0.00359(T-27)$ & $\left(\mathrm{kg} / \mathrm{m}^{3}\right)$ \\
\hline & Specific heat: $C p=1.0057+0.000066(T-27)$ & $\mathrm{J} \mathrm{kg}^{-1} \mathrm{~K}^{-1}$ \\
\hline Back insulation & $\begin{array}{l}\text { Wood shavings } \\
\text { thickness }\end{array}$ & $5 \mathrm{~cm}$ \\
\hline
\end{tabular}




\begin{tabular}{|c|c|c|}
\hline & $\begin{array}{l}\text { Density } \\
\text { Thermal conductivity }\end{array}$ & $\begin{array}{l}140 \mathrm{~kg} \mathrm{~m}^{-3} \\
0.059 \mathrm{~W} \mathrm{~m}^{-1} \mathrm{~K}^{-1}\end{array}$ \\
\hline & thickness & $3 \mathrm{~cm}$ \\
\hline & Density & $820 \mathrm{~kg} \mathrm{~m}^{-3}$ \\
\hline & Thermal conductivity & $0.4 \mathrm{~W} \mathrm{~m}-1 \mathrm{~K}^{-1}$ \\
\hline & $\begin{array}{l}\text { glass wool } \\
\text { Density } \\
\text { Thermal conductivity }\end{array}$ & $\begin{array}{l}200 \mathrm{~kg} \mathrm{~m}^{-3} \\
0.04 \mathrm{~W} \mathrm{~m}^{-1} \mathrm{~K}^{-1}\end{array}$ \\
\hline Modulus frame & Height at outlet & $75 \mathrm{~cm}$ \\
\hline & Height at inlet & $44 \mathrm{~cm}$ \\
\hline & Length & $206 \mathrm{~cm}$ \\
\hline & Width & $96.5 \mathrm{~cm}$ \\
\hline & tilt angle & $8.65^{\circ}$ \\
\hline
\end{tabular}

\subsubsection{Ambient temperature and sky temperature}

The ambient temperature during the time of the air heater testing was estimated from its experimental average value and the index of clearness given by [9].

$T_{a}(h)=\overline{T_{a}}+\left(25.8 \bar{K}_{T}-5.21\right) \times$

$\sum_{n=1}^{4} c_{n}\left[\cos \frac{2 \pi n}{24}(t-1)-B_{n}\right]$

Where $\mathrm{B}_{1}=3.805, \mathrm{~B}_{2}=0.360, \mathrm{~B}_{3}=0.822, \mathrm{~B}_{4}=3.513, \mathrm{c}_{1}=0.4632, \mathrm{c}_{2}=0.0984, \mathrm{c}_{3}=0.0168, \mathrm{c}_{4}=0.0138$ and $\bar{K}_{T}=\frac{G_{0}}{G}$ the index of clearness given by the ratio of the total radiation received on a plan over the extraterrestrial total radiation

To calculate $T_{a}$ from the relation (21), G was calculated from the extraterrestrial total radiation formula and $\bar{T}_{a}$ and $G_{0}$ were obtained from experimental data presented in Table 2.

The Blackbody-equivalent sky temperature is expressed by the formula of Swinbank [10] given by:

$T_{s}=0.0552 T_{a}^{1.5}$

\subsubsection{Heat transfer coefficients}

Radiative heat transfer coefficient on the cover

The radiation heat transfer coefficient between the surface of the cover and the sky can be expressed by referring to the ambient temperature as:

$h_{r 1 s}=\sigma \varepsilon_{1}\left(T_{1}^{2}+T_{s}^{2}\right) \frac{T_{1}^{2}-T_{s}^{2}}{T_{1}-T_{a}}$

\section{Convective heat transfer coefficient of the wind}

Under the climatic conditions of the experimental site, the wind velocity is lower than $5 \mathrm{~m} / \mathrm{s}$. So, the convective transfer coefficient between the wind and both glass cover and back insulation can be estimated from the formula of McAdams [11] as:

$h_{w}=5.7+3.8 \mathrm{~V}$

Radiative heat transfer coefficient between the cover and the absorber plate

The coefficient $h_{r 12}$ is deduced from the formula of the radiative heat transfer coefficient between two parallel plates given by the following relation:

$h_{r 12}=\frac{\sigma\left(T_{2}^{2}+T_{1}^{2}\right)\left(T_{1}+T_{2}\right)}{\frac{1}{\varepsilon_{1}}+\frac{1}{\varepsilon_{2}}-1}$

Natural convective heat transfer coefficient between the cover and the absorber plate

The convective heat transfer coefficient $h_{12}$ between the cover and the non-porous absorber plate is estimated from the relationship of Hollands [12] linking Nusselt and Rayleigh numbers for natural convection between inclined planes lying in the range $0<\mathrm{Ra}<10^{5}$ and $\beta \leq 75^{\circ}$.

$N u=1+1.44\left[1-\frac{1708}{R_{a} \cos \beta}\right]^{+} \times$
$\left[1-\frac{1708}{R_{a} \cos \beta}\right]+\left[\left(\frac{R_{a} \cos \beta}{5830}\right)^{1 / 3}-1\right]^{+}$ 
Using this correlation, the suitable equivalent diameter is the distance between the cover and the plate. Also, the notation [ $]^{+}$is used to signify that if the quantity in the bracket is negative, it should be set equal to zero.

Table 2: Typical days of months, global radiation and climatic data of the site $\left(12^{\circ} 20-12^{\circ} 26 \mathrm{~N}, 1^{\circ} 20-1^{\circ} 36 \mathrm{~W}\right)$ [8]

\begin{tabular}{lllllll}
\hline Month & $\begin{array}{l}\text { No of the typical day in the } \\
\text { month }\end{array}$ & $\begin{array}{l}\text { No of the typical } \\
\text { day in the year }\end{array}$ & $\begin{array}{l}\text { wind velocity } \\
(\mathrm{m} / \mathrm{s})\end{array}$ & $\begin{array}{l}\text { Static } \\
\text { pressure } \\
\left(10^{2} \mathrm{~Pa}\right)\end{array}$ & $\begin{array}{l}\bar{T}_{a} \\
\left({ }^{\circ} \mathrm{C}\right)\end{array}$ & $\begin{array}{l}\bar{G}_{0 h} \\
\left(\mathrm{MJ}^{-m^{2}}\right. \\
\left.\mathrm{dav}^{-1}\right)\end{array}$ \\
\hline $\begin{array}{l}\text { January } \\
\text { February }\end{array}$ & 17 & 17 & 2.55 & 977.15 & 25.9 & 15.94 \\
March & 16 & 47 & 2.65 & 975.80 & 29.185 & 17.94 \\
April & 15 & 75 & 2.45 & 974.85 & 32.07 & 18.71 \\
May & 15 & 105 & 2.50 & 973.65 & 33.63 & 18.60 \\
June & 11 & 135 & 2.95 & 975.15 & 32.6 & 18.97 \\
July & 17 & 162 & 2.95 & 977.25 & 30.585 & 18.52 \\
August & 16 & 198 & 2.25 & 977.65 & 27.9 & 17.09 \\
September & 15 & 228 & 1.95 & 977.75 & 27.28 & 15.68 \\
October & 15 & 258 & 1.95 & 977.05 & 28 & 17.38 \\
November & 14 & 288 & 1.80 & 976.20 & 30.05 & 17.84 \\
December & 11 & 318 & 1.50 & 975.90 & 28.12 & 16.89 \\
\hline
\end{tabular}

Convective heat transfer coefficient between airstream and porous absorber wall $\left(\mathrm{h}_{\mathrm{sf}}\right)$

The heat transfer coefficient $h_{s f}$ was deduced from the Nusselt number expression given by Achenbach [13] for convective heat transfer at the wall for fluid flow in a horizontal porous plate channel:

$$
N u=\left(1-\frac{d_{a}}{D_{h}}\right) \operatorname{Re}_{D_{h}}^{0.61} \operatorname{Pr}^{1 / 3}
$$

Where $d_{a}$ is the diameter of the aluminum wire making the porous absorber mesh $\left(d_{a} \approx 0.45 \mathrm{~mm}\right)$ and $D_{h}$ the equivalent hydraulic diameter of the useful duct.

Convective heat transfer coefficients between the airstream and the non-porous absorber wall $\left(h_{2 f}\right)$ and between the airstream and back insulation wall $\left(h_{3 f}\right)$

For a fully developed airstream flow in duct, heat transfer coefficients $h_{2 f}, h_{3 f}$ were estimated from Nusselt number correlation of Tan \& Charters [14] for flows in rectangular duct with uniform heating

$N u=0.018 \operatorname{Re}^{0.8} \operatorname{Pr}^{0.4} \times C$

with :

$C=\left\{\begin{array}{l}1+\frac{D_{h}}{L}\left(14.3 \log \frac{L}{D_{h}}-7.9\right) \text { for } \frac{L}{D_{h}}<60 \\ 1+7.5 \frac{D_{h}}{L} \text { for } \frac{L}{D_{h}}>60\end{array}\right.$

Where $L$ is the duct length and $D_{h}$ the equivalent hydraulic diameter given by $D_{h}=\frac{4 A_{c}}{P}$; with $A_{c}$ the cros-section of the duct and $P$ its perimeter. 


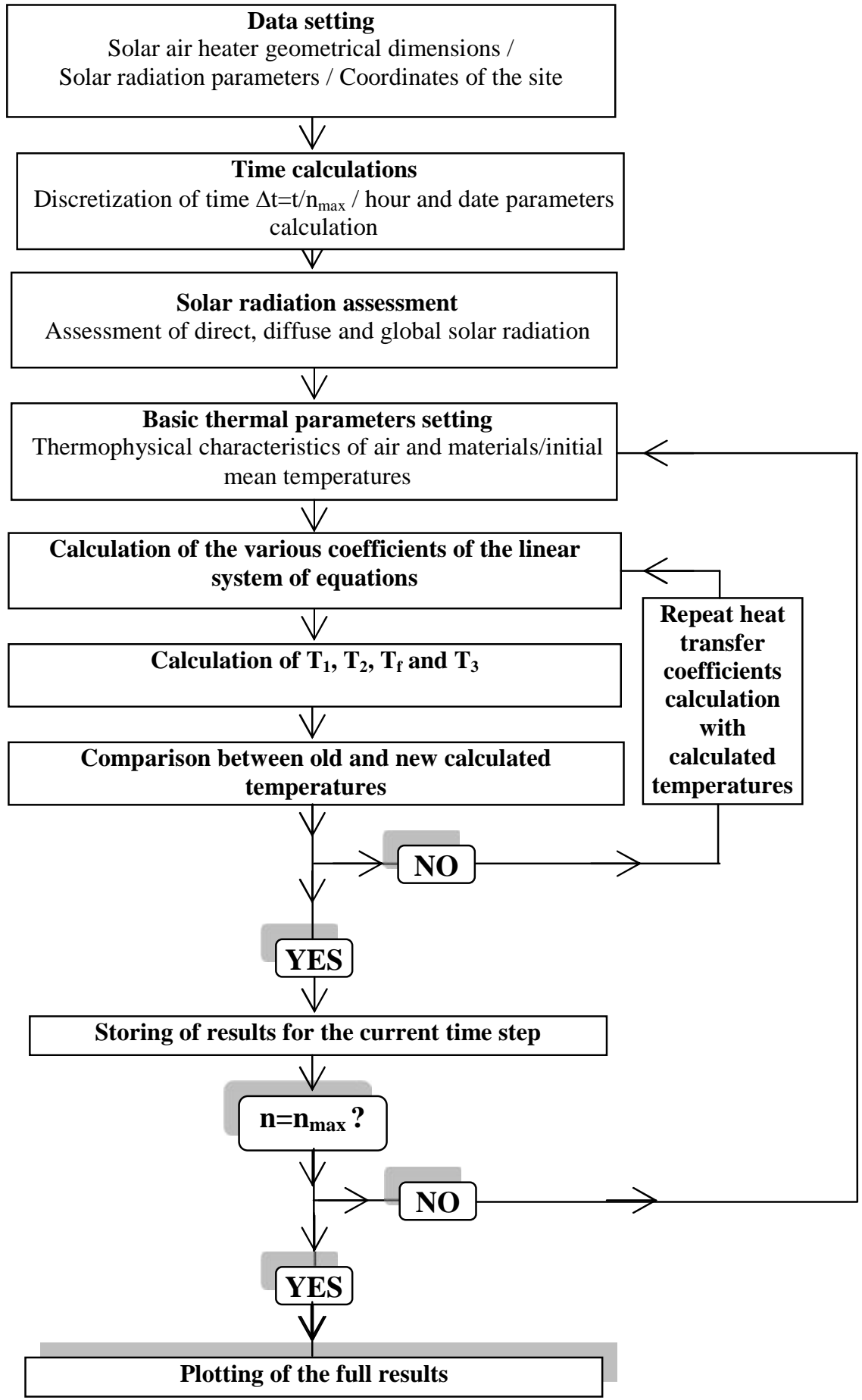

Figure 2: Flowchart of the simulation program sequence

\subsection{Steady state thermal performances assessment}

\subsubsection{Overall heat loss coefficient $\left(U_{\mathrm{L}}\right)$}

For such a collector, thermal losses are assumed to be linear and the overall heat loss flux can be stated as:

$$
q_{\text {loss }}=U_{L}\left(T_{2}-T_{a}\right)
$$

Where the overall heat loss coefficient $U_{L}$ is equal to the sum of heat loss coefficients at top $\left(U_{t}\right)$, the bottom $\left(U_{b}\right)$ and the lateral sides $\left(U_{s}\right)$ of the air heater.

$U_{L}=u_{t}+u_{b}+u_{s}$

With: 
$u_{t}=\left[\frac{1}{h_{12}+h_{r 21}}+\frac{1}{h_{w}+h_{r 1 s}}\right]^{-1}$

$u_{b}=\frac{1}{\sum_{1}^{n} \frac{y_{i}}{\lambda_{i}}+1 / h_{w}}$

$u_{s}=\frac{1}{\sum_{1}^{m} \frac{y_{i}}{\lambda_{i}}+1 / h_{w}}$

Where $n$ and $m$ are the numbers of insulation layer of respectively the bottom and the sides, $y_{i}$ the thickness of the $i$-th layer of bottom or lateral insulation and $\lambda_{i}$ the thermal conductivity of the $i$-th layer material

\subsubsection{Efficiency factor, removal factor and useful heat}

The physical interpretation of $F^{\prime}$ is that it represents the ratio of the actual useful heat gain to the useful heat gain that would result if the absorber had been at local airstream temperature. From this definition, the efficiency factor $F$ ' is deduced from the overall heat loss coefficient according to the following relations:

$$
F^{\prime}=\frac{\frac{1}{U_{L}}}{\frac{1}{h_{2 f}+h_{s f}}+\frac{1}{U_{L}}}
$$

Typically, the heat removal factor FR represents the ratio of the actual useful heat gain and that would result if the absorber had been at the inlet air temperature.

Assuming that $F^{\prime}$ and $U_{L}$ were independent of the position, the removal factor is calculated as:

$F_{R}=\frac{\dot{m}_{f} C_{p f}}{S U_{L}}\left[1-\exp \left(-\frac{S U_{L} F^{\prime}}{\dot{m}_{f} C_{p f}}\right)\right]$

Usually, the useful heat is expressed according to the inlet and outlet temperatures as [2,4]:

$Q_{u}=\dot{m}_{f} C_{p f}\left(T_{f o}-T_{f i}\right)$

Under steady-state conditions, this useful heat can also be expressed using successively the efficiency factor and the removal factor as:

$Q_{u}=S F^{\prime}\left[\left(\tau_{1} \alpha_{2}\right) G_{0}-U_{L}\left(T_{f}-T_{a}\right)\right]$
$Q_{u}=S F_{R}\left[\left(\tau_{1} \alpha_{2}\right) G_{0}-U_{L}\left(T_{f i}-T_{a}\right)\right]$

The equality between these two expressions of the useful heat allows to establish a direct correlation between F' and $F_{\mathrm{R}}$ and to deduce the expression of the mean temperature:

$\frac{F^{\prime}\left[\left(\tau_{1} \alpha_{2}\right) G_{0}-U_{L}\left(T_{f}-T_{a}\right)\right]}{F_{R}\left[\left(\tau_{1} \alpha_{2}\right) G_{0}-U_{L}\left(T_{f i}-T_{a}\right)\right]}=1$

By introducing the temperature $T_{f e}$ in the numerator of equation (39), we have:

$\frac{F^{\prime}}{F_{R}}\left[1-\frac{U_{L}\left(T_{f}-T_{f i}\right)}{\frac{Q_{u}}{F_{R}}}\right]=1$

Hence :

$\frac{U_{L}\left(T_{f}-T_{f i}\right)}{\frac{Q_{u}}{F_{R}}}=1-\frac{F_{R}}{F^{\prime}}$

One can then deduce the mean temperature of the fluid by:

$T_{f}=T_{f i}+\frac{Q_{u}}{F_{R} U_{L}}\left(1-\frac{F_{R}}{F^{\prime}}\right)$ 


\subsubsection{Air heater efficiency}

The air heater efficiency is defined as the ratio of its useful heat, at any moment of its operation, by the incident solar radiation power falling on its surface during the same moment. Therefore, by taking into account Eq. (41), the overall efficiency can be written as:

$\eta=\frac{Q_{u}}{S G_{0}}=\frac{F_{R} F^{\prime} U_{L}}{\left(F^{\prime}-F_{R}\right) S G_{0}}\left(T_{f}-T_{f i}\right)$

Hence:

$\eta=\frac{F_{R} U_{L}}{\left(1-F^{\prime \prime}\right) S G_{0}}\left(T_{f}-T_{f i}\right)$

With $F^{\prime \prime}$ the air heater flow factor given by $F^{\prime \prime}=F_{R} / F^{\prime}$

Using Eqs. (37) and (38), the efficiency can be respectively stated using separately $F^{\prime}$ and $F_{R}$ as :

$\eta=F^{\prime}\left[\left(\tau_{1} \alpha_{2}\right)-U_{L} \frac{T_{f}-T_{a}}{G_{0}}\right]$

$\eta=F_{R}\left[\left(\tau_{1} \alpha_{2}\right)-U_{L} \frac{T_{f i}-T_{a}}{G_{0}}\right]$

The term $\eta_{1}=F^{\prime}\left(\tau_{1} \alpha_{2}\right)$ is the energy conversion factor and represents the maximum efficiency of the air heater. The equation (43) shows that, in theory, the efficiency decreases linearly with the term $\frac{T_{f}-T_{a}}{G_{0}}$ if the efficiency factor $\mathrm{F}^{\prime}$, and the overall heat loss coefficient $U_{\llcorner}$remain constant.

The term $\left(\tau_{1} \alpha_{2}\right)$ denotes the transmittance-absorptance product of the air heater given by:

$$
\left(\tau_{1} \alpha_{2}\right)=\tau_{1} \alpha_{2} \sum_{n=1}^{\infty}\left[\left(1-\alpha_{2}\right) \rho_{d}\right]^{n} \approx \frac{\tau_{1} \alpha_{2}}{1-\left(1-\alpha_{2}\right) \rho_{d}}
$$

Where $\rho_{d}$ is the unpolarized diffuse fraction of the energy repetitively reflected by the non-absorber iron sheet.

Equations (43) and (44) show explicitly that efficiency increases with the optical efficiency $\left(\tau_{1} \alpha_{2}\right)$ and the incident solar radiation power $G_{0}$; and decreases with the overall heat loss coefficient $U_{L}$. These trends confirm that the thermal performances of the air heater are improved by minimizing at the same time the optical losses (by using a suitable transparent cover) and the thermal losses at the top, the bottom and sides of the heater.

\section{RESULTS AND DISCUSSIONS}

\subsection{Simulated annual characteristics of the solar heater}

\subsubsection{Incident radiation, energy converted and useful power \\ Incident radiation, absorbed power and useful} power of the air heater were simulated for the typical days of the twelve (12) months of the year (Table 2); and showed in Figs. 3a,3b, 3c and 3d. These typical daily variation curves were established for $1 \mathrm{~m}^{2}$ of collecting surface on the experimental site located at $12^{\circ} 21^{\prime} \mathrm{N}$. It can be noticed from these figures that for the whole months of the year, the sun shines all these days for several hours with an insolation duration reaching usually 12 hours between $6 \mathrm{~h}$ and $18 \mathrm{~h}$. The highest insulation are observed during the months of March, April and September with incident radiation reaching respectively maxima of 926,925 and $923 \mathrm{~W} / \mathrm{m}^{2}$ at solar midday.

The thermal power absorbed by the collector and the useful power transferred to the airstream were shown on Figs. $3 a$ and $3 b$. These powers show their highest values occurrence in months of April and September. For the typical days of these months, the power recovered by the absorber presents respective maxima of $757,755 \mathrm{~W} / \mathrm{m}^{2}$ at solar midday. For the whole months of the year, the density power absorbed at solar midday of a typical day is always higher than
$670 \mathrm{~W} / \mathrm{m}^{2}$. The mean transmittance-absorptance $\left(\tau_{1} \alpha_{2}\right)$ product (also call optical efficiency) of the whole typical days approaches a mean value of 0.81 showing that about $81 \%$ of the incident radiant energy is recovered by the solar heater. The energy fraction yields to the airstream per $\mathrm{m}^{2}$ of collecting surface ranges from around $100 \mathrm{~W} / \mathrm{m}^{2}$ in January and December to 500 $\mathrm{W} / \mathrm{m}^{2}$ in March, April and September. These results show that the solar heater can gain energy between $6 \mathrm{~h} 00$ and $18 \mathrm{~h} 00$ of a typical day according to the month of the year, whereas the airstream can only carry away useful heat between $6 \mathrm{~h}: 00$ and 17h00.

\subsubsection{Air heater temperatures}

The daily variations of the air temperatures for the typical days of the 12 months of the year are shown on Figs. 4a\&b. Mean temperature profiles of glass cover, absorber and outlet air were then illustrated for time ranging between sunrise and sunset of typical day of each month.

For the glass cover: or the 12 months of the year, the temperature changes by following the race of the sun between the ambient temperature and $90^{\circ} \mathrm{C}$. It presents a maximum value ranging between $78^{\circ} \mathrm{C}$ (for March) and $87^{\circ} \mathrm{C}$ (for April) according to the month.

For absorber: For most part of the day, the mean temperature of the absorber changes with the position of the sun between the ambient temperature and $115^{\circ} \mathrm{C}$. The mean temperature of the absorber 
reaches its maximum around solar midday and this is 102 (for March) and $114^{\circ} \mathrm{C}$ (for April).

For outlet air: The temperature curves of outlet air for the typical day of each month shows that the temperature of airstream at the useful duct outlet varies significantly with the hour of the day. Temperatures vary according to the time of the day and follow the rays of the sun with a significant dephasing of about one hour.
Thus, it reaches its maximum value ranging between $61^{\circ} \mathrm{C}$ (for a day of March) to $67^{\circ} \mathrm{C}$ (for a typical day of April) almost one hour after midday. This delay in the outlet air temperature variation could result from the high thermal transfer inertia between the porous absorber and the airstream due to higher values of Fourier's number at the interface between absorber and airstream. Which may also be due to the high resistance to the transfer of energy by conduction in the airstream.
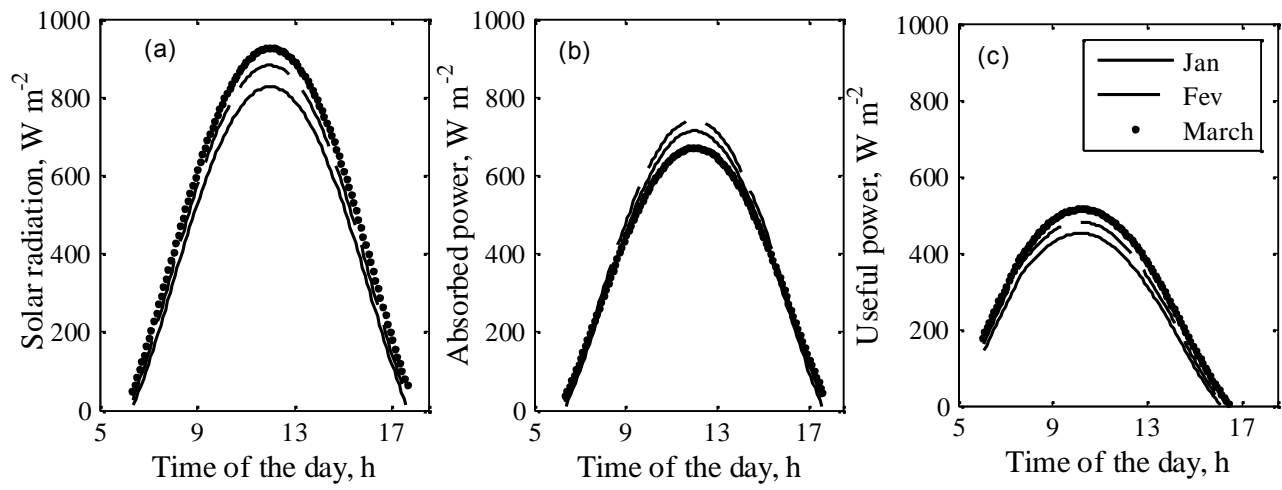

Figure 3a: Hourly variation of (a) solar radiation, (b) power absorbed by the air heater and (c) useful heat of the air heater, for typical days from January to March.
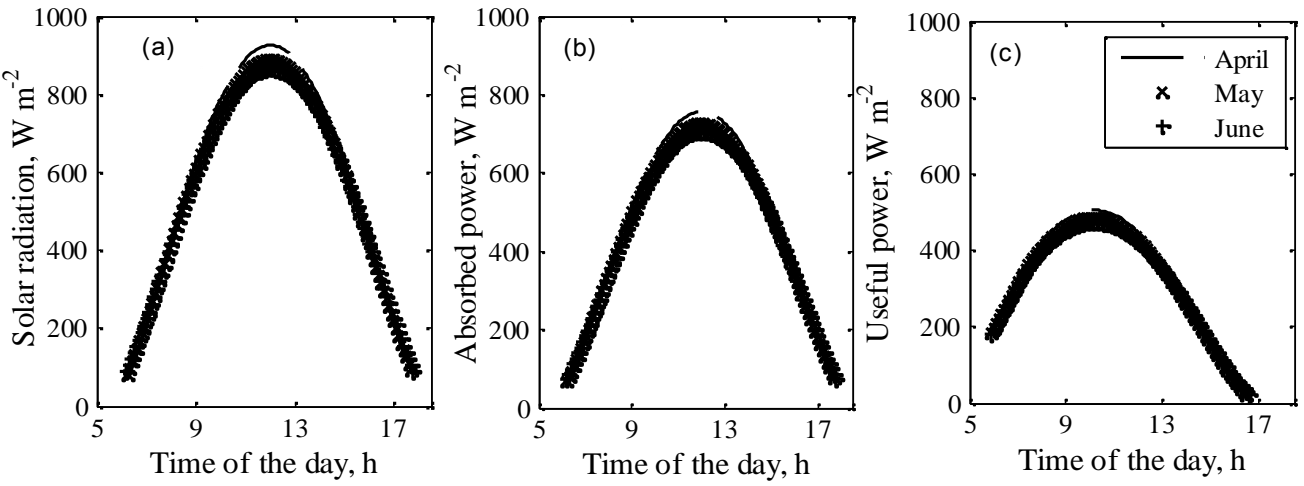

Figure 3b: Hourly variation of (a) solar radiation, (b) power absorbed by the air heater and (c) useful heat of the air heater, for typical days from January to March.
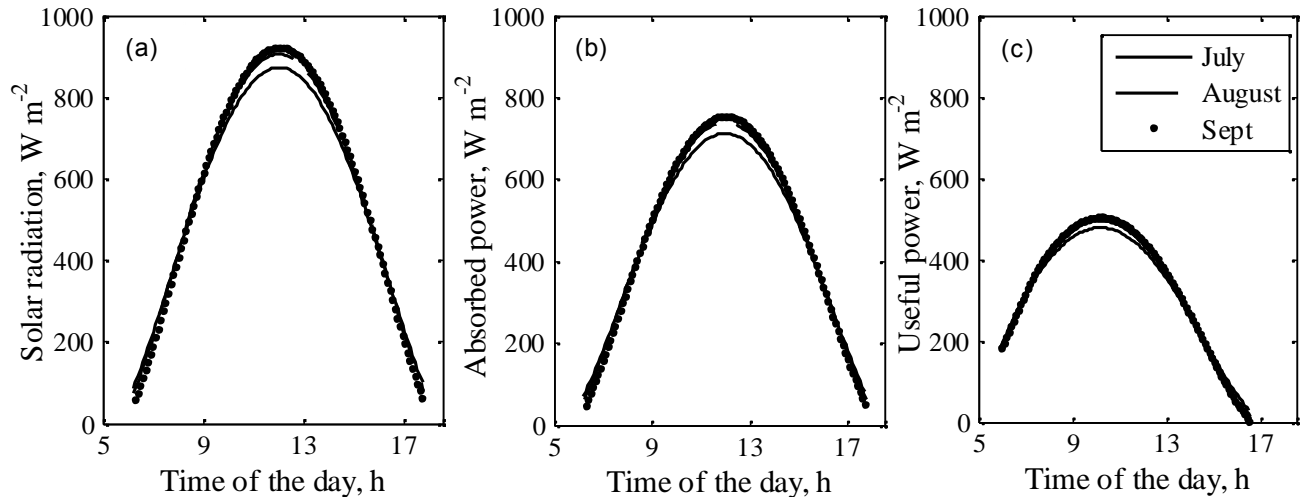

Figure 3c: Hourly variation of (a) solar radiation, (b) power absorbed by the air heater and (c) useful heat of the air heater, for typical days from July to September. 

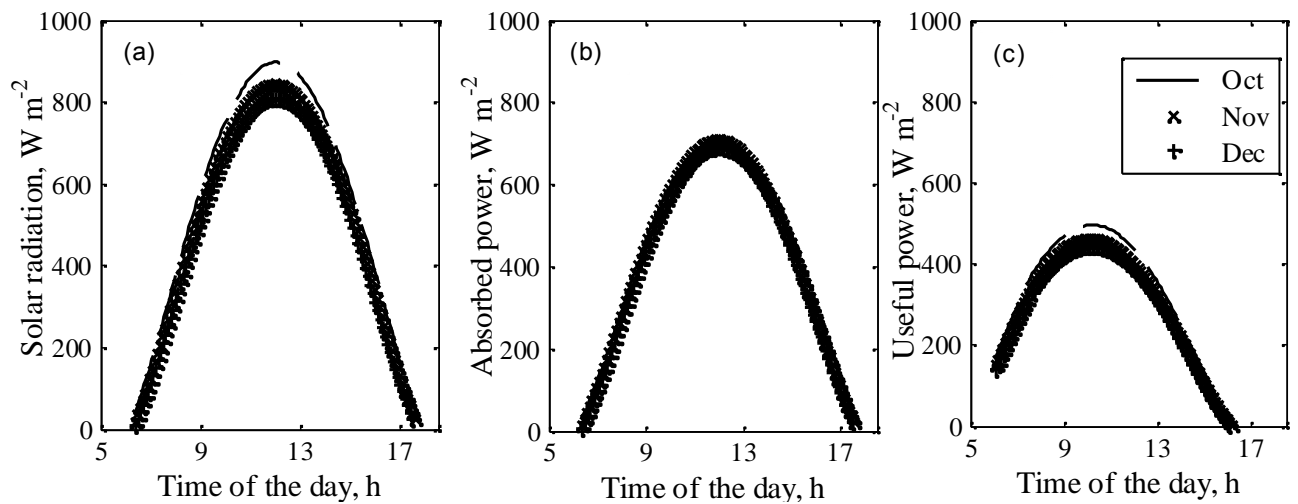

Figure 3d: Hourly variation of (a) solar radiation, (b) power absorbed by the air heater and (c) useful heat of the air heater, for typical days from October to December.

\subsection{Thermal performance of the solar heater}

In order to compare theoretical and experimental data, only thermal performances of a day of June were calculated and plotted (fig.5). It is noted that the removal factor FR and the overall heat lost coefficient UL reach their optimal values at solar midday with a maximum value of 0.45 for $F R$ and a minimum value of $5.4 \mathrm{~W} \mathrm{~m}^{-2}$ $\mathrm{K}^{-1}$ for UL; with a corresponding solar radiation of 865 $\mathrm{W} / \mathrm{m}^{2}$ and a useful power of $532 \mathrm{~W} / \mathrm{m}^{2}$. From Fig5a, the overall losses are very high at the beginning and the end of the day and almost constants in the middle of day i.e. between $10 \mathrm{~h}$ and $14 \mathrm{~h}$. The removal factor varies inversely with the overall losses while following the sun race. The average values of $\mathrm{FR}$ and $\mathrm{UL}$ deduced theoretically are 0.4 and $7.20 \mathrm{~W} \mathrm{~m}^{-2} \mathrm{~K}^{-1}$ respectively.

From Fig.5b, the classical straight line of thermal efficiency vs. $\left(T_{f}-T_{f i}\right) / G_{0}$ was plotted. The curve has a slope of $-2.40 \mathrm{~W} \mathrm{~m}^{-2} \mathrm{~K}^{-1}$ (corresponding theoretically to the product $-F^{\prime} x U L$ ) and a maximum value of efficiency at solar midday of 0.6157 (corresponding theoretically to the product $F^{\prime}\left(\tau_{1} \alpha_{2}\right)$ ). From the value of the product F'xUL $\left(2.40 \mathrm{~W} \mathrm{~m}^{-2} \mathrm{~K}^{-1}\right)$ given by the slope of the straight line of Fig5b and that of mean UL $\left(7.20 \mathrm{~W} \mathrm{~m}^{-2} \mathrm{~K}^{-1}\right)$ calculated from the data of UL and FR plotted on Fig5a, it can be deduce an average value of $F^{\prime}$ to $0.33 \mathrm{~W} \mathrm{~m}^{-2}$ $\mathrm{K}^{-1}$.
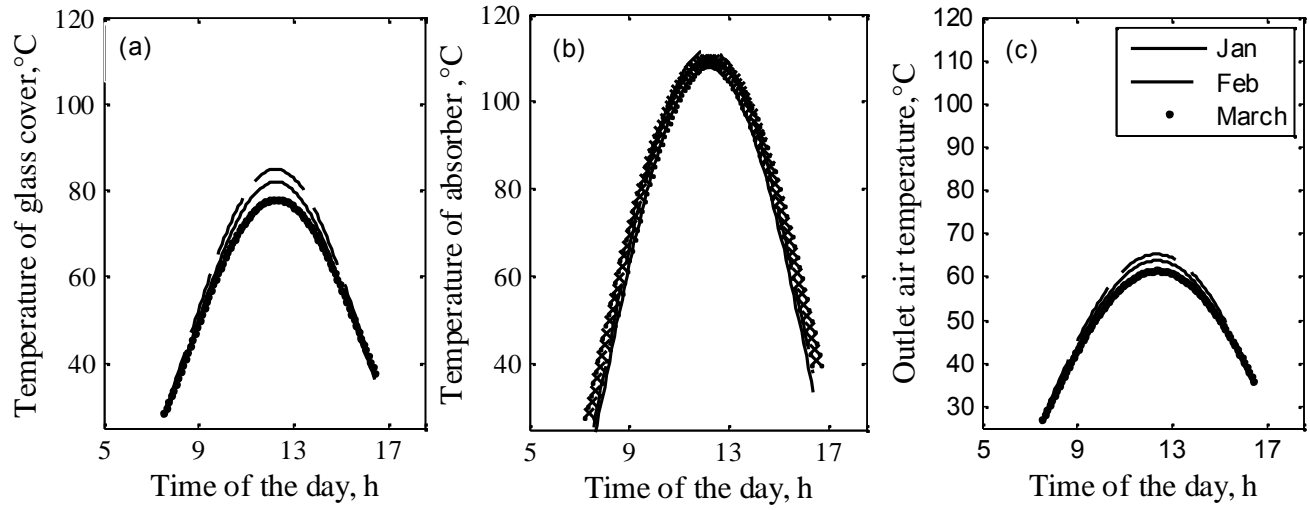

Figure 4a: Hourly variation of the air heater temperatures for typical days from January to Mars: (a) glass cover (b) combined absorber (c) outlet air temperature
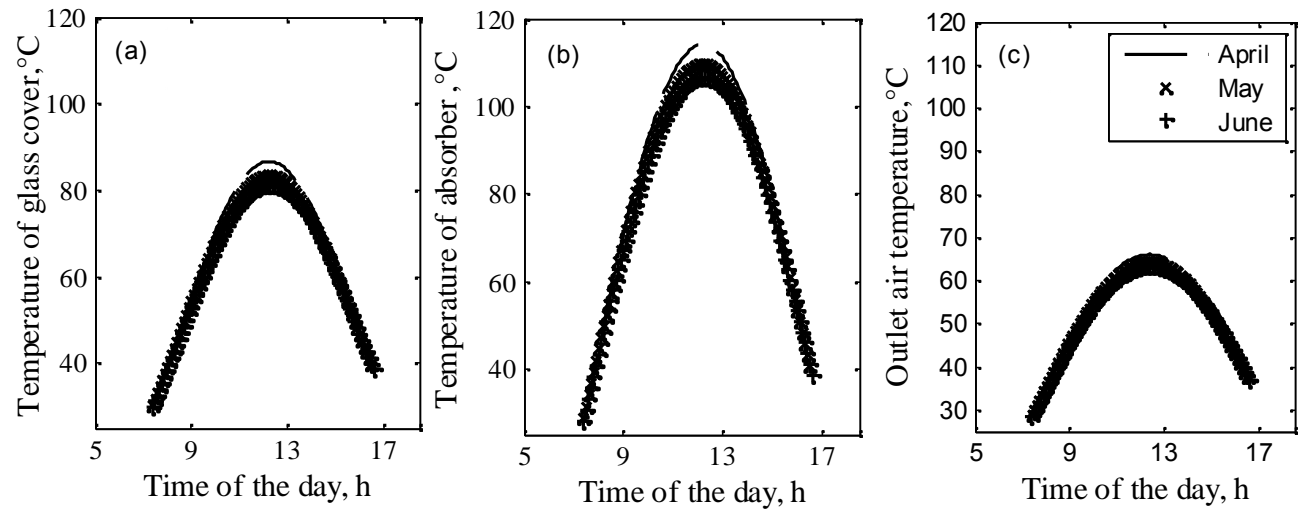

Figure 4b: Hourly variation of the air heater temperatures for typical days from April to June: (a) glass cover (b) combined absorber (c) outlet air temperature 

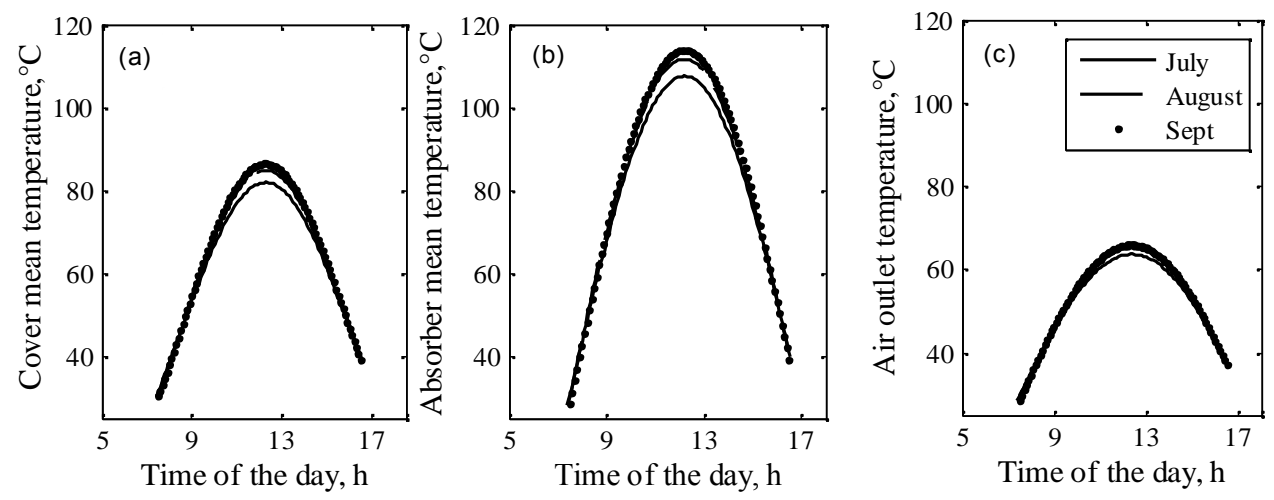

Figure 4c: Hourly variation of the air heater temperatures for typical days from July to September: (a) glass cover (b) combined absorber (c) outlet air temperature
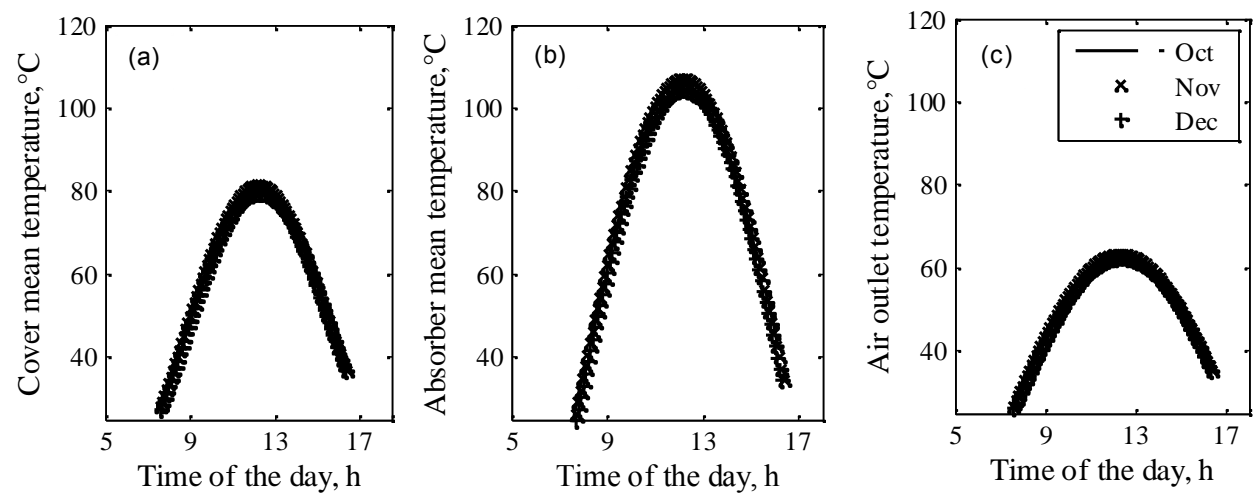

Figure 4d: Hourly variation of the air heater temperatures for typical days from October to December: (a) glass cover (b) combined absorber (c) outlet air temperature

\subsection{Experimental data vs. theoretical results} With a view to compare theoretical results to experimental data, simulated and experimental temperatures profiles were plotted on Figs $6 a, 6 b, 7 a$ and $7 \mathrm{~b}$. We can easily note that for the whole parameters (temperatures as well as thermal efficiency and useful heat power), the experimental curves are close to simulated ones for the first half of the day. This corresponds to operating hours located before solar midday (with $R^{2} \approx 0.987$ ). The difference between these curves becomes more important after solar midday. When experimental curves are always above the theoretical curves with the exception of thermal efficiency curves. These major difference between simulated and experimental temperatures in the afternoon could be due to several reasons that will be raised in the following sections.

\subsubsection{Solar heater temperatures}

In the current work, averages values of experimental data were considered. These mean temperature values are presented in Fig.6(a\&b). Fig.6(a) and Fig.6(b) show that both theoretical and experimental air heater temperatures change during the day by following the sun. Contrary to calculated values, the experimental temperature values reach their maximum at around 13:00 i.e. one hour after solar noon. The maximum temperatures reached for the glass cover, the absorber and the outlet air are respectively about $82^{\circ} \mathrm{C}, 109{ }^{\circ} \mathrm{C}$ and $61.8^{\circ} \mathrm{C}$ whereas the ambient temperature was 38.25 ${ }^{\circ} \mathrm{C}$. Experimental maximum values are close to those simulated which are about $83.52{ }^{\circ} \mathrm{C}, 109.8{ }^{\circ} \mathrm{C}$ and $64.50^{\circ} \mathrm{C}$ respectively for the cover glass, the absorber and the outlet air. From Figs $6 \mathrm{a}$ and $6 \mathrm{~b}$, we observe that experimental and simulated curves agree especially for hours before solar noon (with $\mathrm{R}^{2} \approx 0.988$ ). 

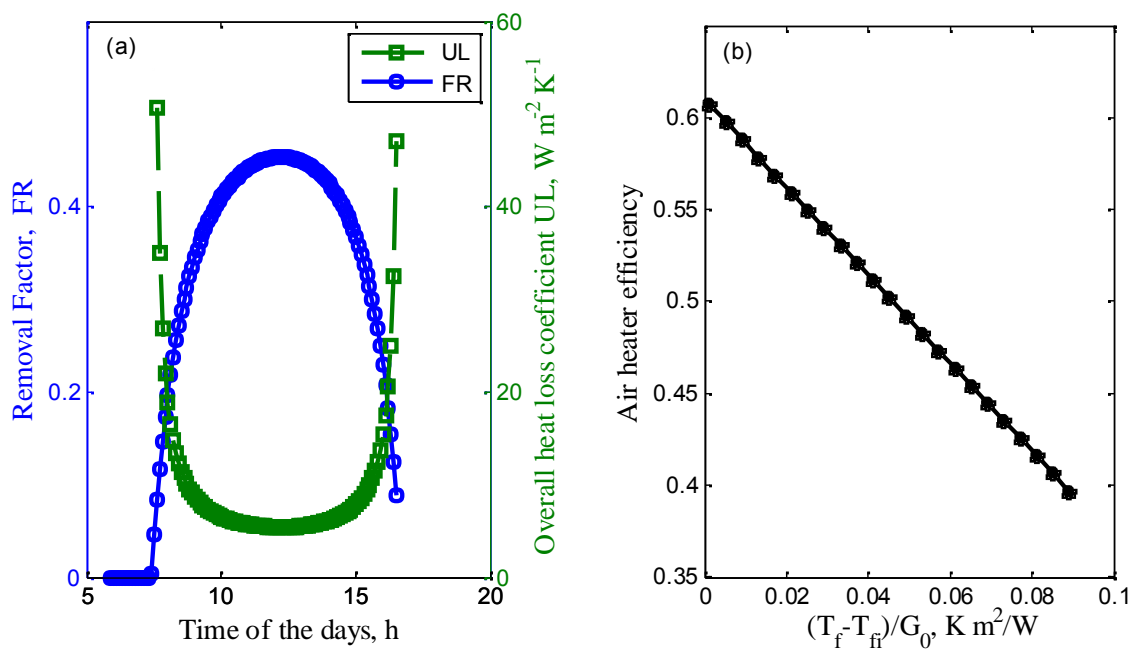

Figure 5: Thermal performances of the air heater: (a) hourly variation of the removal factor and the overall heat loss coefficient for June, $10^{\text {th }}$, (b) efficiency vs. $\Delta T / G$

For hours beyond solar noon, the difference between these curves becomes increasingly significant and experimental values attain their highest values. These significant difference noticed in the afternoon between experimental and simulated temperatures can be justified by several reasons among which are (i) the assumption that the physical properties of materials used are constant and that the conduction in solid and gas phases in the useful duct are negligible, and (ii) the use of components mean temperatures in the model. Indeed, when modeling the solar heater by assuming mean temperatures, constant physical properties and negligible specific heat of materials, one neglects the components heat capacity effect and accordingly the system thermal inertia. Consequently, the fraction of heat stored by the solar heater components that contributes to rise in temperatures during the day is not taken into account. Therefore, the simulated temperatures are lower than the measured ones.

The temperatures obtained for our solar heater are close to the range of typical values of temperatures given by former works. They are slightly above those found by Jain and Jain [15] when studying an inclined multi-pass solar air heater with two cover glasses and a thermal storage system (with an ambient temperature ranging between 20 and $30^{\circ} \mathrm{C}$, an air flow of $a=0.028$ $\mathrm{kg} \mathrm{s}^{-1}$, a collecting surface of $4 \mathrm{~m}^{2}$ and a slope of $30^{\circ}$ ).
The absorber temperature of this solar heater ranged between 20 and $90^{\circ} \mathrm{C}$ in October and the rises in air temperature reached $22^{\circ} \mathrm{C}$ at solar noon. Our solar heater temperatures are also widely above the range of temperatures of six (06) different types of solar heater studied by Koyuncu [5] for the drying of agricultural products on the site of Samsun in Turkey. The temperatures of absorbers of these solar heaters ranged from 35 and $80^{\circ} \mathrm{C}$, while the outlet temperatures ranged between 35 and $45^{\circ} \mathrm{C}$ for an ambient temperature fluctuating between 25 and $30^{\circ} \mathrm{C}$, with an air flow rate of about $a=0.023 \mathrm{~kg} \mathrm{~h}^{-1}$ and solar heater tilted of $30^{\circ} \mathrm{C}$.

However, temperatures reach by our solar heater were slightly lower than those obtained throughout simulations by Chemkhi, Zagrouba \& Bellagi [16] for the solar heater of a solar dryer designed for the drying of the agricultural products. For air flows ranging between 0.007 and $0.04636 \mathrm{~kg} \mathrm{~s}^{-1}$ and for ambient temperatures ranging between 20 and $30^{\circ} \mathrm{C}$, the outlet temperature of this solar heater (tilted at $36^{\circ}$ ) can reach $75^{\circ} \mathrm{C}$ while the absorber temperature approaches $100^{\circ} \mathrm{C}$. Our temperatures are also lower than those of Goyal and Tiwari [17] who carried a parametric study of a reverse flat plate absorber cabinet dryer. Around solar noon, the temperature of this flat plate absorber attains $100^{\circ} \mathrm{C}$ whereas outlet air temperature approaches $80^{\circ} \mathrm{C}$. 

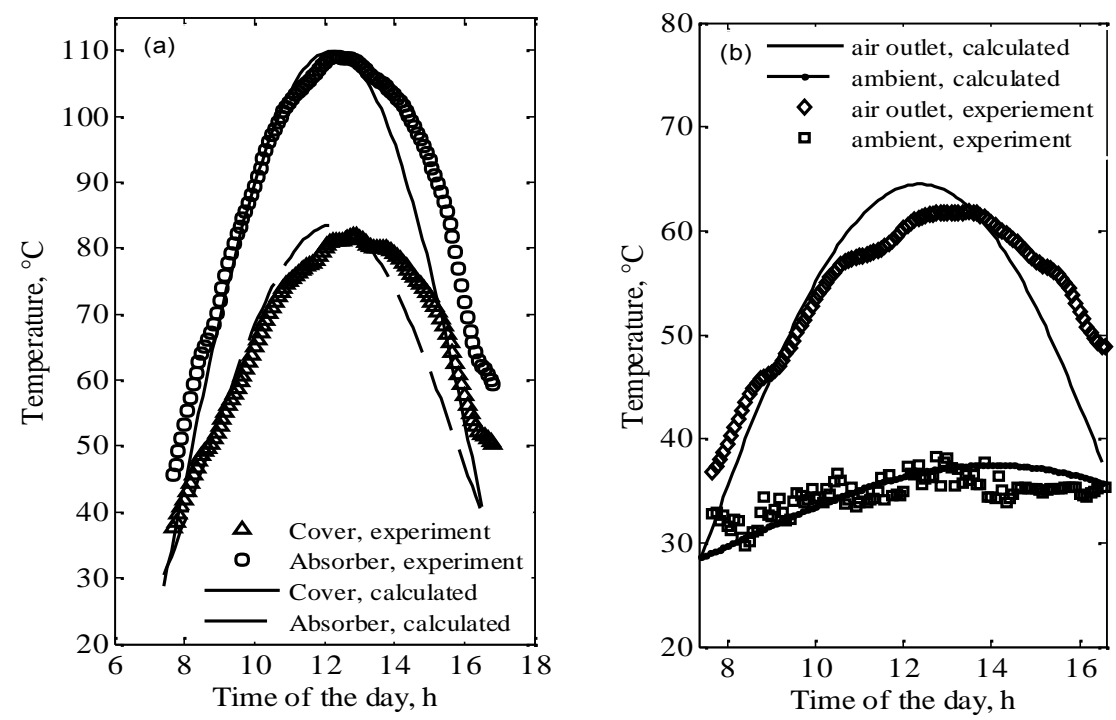

Figure 6: Comparison of predicted and experimental temperatures: (a) cover \& absorber, (b) ambient \& outlet air.

\subsubsection{Solar heater performances}

The efficiency curve was plotted for both simulated and experimental data on Fig.7(a). In experiments, the solar air heater has a thermal efficiency of about $62 \%$ at solar noon (for a global radiation of almost $850 \mathrm{~W} / \mathrm{m}^{2}$, an air flow of $0.023 \mathrm{~kg} / \mathrm{s}$ and an ambient temperature about of $35^{\circ} \mathrm{C}$ ). The experimental curve firmly agrees with the theoretical curve for $\Delta T / G_{0}$ lower than 0.04. For the values of $\Delta T / G_{0}$ higher than 0.04 , an increasing difference was observed between the experimental and simulated data. This deviation may be related to the neglect of the heat capacity effects in the quasi-steady modeling, as previously observed. This deviation is also seen in the useful powers plots on Fig.7(b). It can also be seen that beyond solar noon, the experimental useful power is always higher than the simulated ones. Taking into account these considerations, the experimental results appear to be more realistic. Also, in order to determine the thermal performance parameters of the solar heater, we carried out a linear fitting of the experimental efficiencies. The values of the products $F^{\prime}\left(\tau_{1} \alpha_{2}\right)$ and $F^{\prime} U L$ deduced from this linear fitting are respectively 0.66 and $5.7 \mathrm{~W} \mathrm{~m}^{-2} \mathrm{~K}^{-1}$. The values of $\mathrm{F}^{\prime}$ and FR estimated from these experimental data and the value UL $\left(7.2 \mathrm{~W} \mathrm{~m}^{-2} \mathrm{~K}^{-1}\right)$ are respectively 0.79 and 0.63 . The value 0.83 of $\left(\tau_{1} \alpha_{2}\right)$ deduced from these results is very close to the calculated value 0.81 . These theoretical and experimental data show that our solar heater has very suitable thermal performances compared to those studied in former works. The performance parameters are higher than those found by Madhlopa, Jones \& Kalenga [18] for "porous" and "wood plate" solar heater which have efficiencies of $21.3 \%$ and $17 \%$ respectively (under the following conditions $\left.\mathrm{G}_{0}=1168 \mathrm{~W} / \mathrm{m}^{2}, \quad \mathrm{~T}_{\text {air }}=31^{\circ} \mathrm{C}, \quad \mathrm{V}_{\text {air }}=1.5 \mathrm{~m} / \mathrm{s}\right)$. The performances of our solar heater are also better than those of: (i) the six different types of natural convection solar air heater studied by Koyuncu [5] with efficiencies of $42.11,45.88,44.23,39.76,39.05$ and $36.94 \%$, (ii) the force convective solar dryer studied by Ayensu [19] has an efficiency of $21.0 \%$, (iii) the reverse flat plate collector of the cabinet dryer of Goyal \& Tiwari [17] has $13.0 \%<\eta<19 \%$ ), (iv) and the solar heater studied by Abdelhamid and al. [20], has $\mathrm{G}_{0}=900 \mathrm{~W} / \mathrm{m}^{2}$ and $\eta=18 \%$. The thermal performances obtained for our solar air heater are of the same order of magnitude as those presented in the studies of Mohamad [3] for a high efficiency solar air heater with simple glazing and an efficiency ranging between 25 and $80 \%$ and AboulEnein et al [6] for the parametric study of solar air heater with and without thermal storage for solar drying applications. The values of the products $F^{\prime}\left(\tau_{1} \alpha_{2}\right)$ and F'UL found were 0.582 and $5.55 \mathrm{~W} \mathrm{~m}^{-2} \mathrm{~K}^{-1}$ for the heater without heat storage and 0.55 and $3.766 \mathrm{~W} \mathrm{~m}^{-2} \mathrm{~K}^{-1}$ for the heater with heat storage, (iii) Abu-Hamdeh [7] for the simulation study of solar air heater has $F^{\prime}\left(\tau_{1} \alpha_{2}\right)$ and $F^{\prime} U L$ at $\quad 0.50$ and $4.5 \quad \mathrm{~W} / \mathrm{m}^{2} \mathrm{~K}$ respectively. 

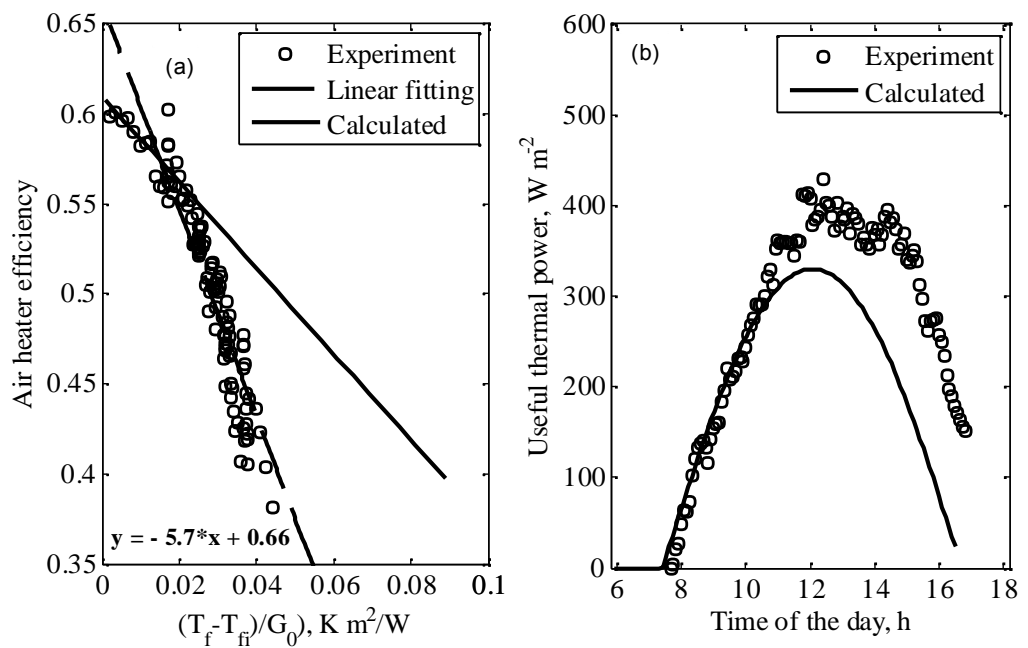

Figure 7: Comparison of predicted and experimental thermal performances: (a) air heater efficiency, (b) useful thermal power.

\section{CONCLUSION}

This work aims to study the quasi-steady state thermal performances of a solar air heater with a combined absorber. The energy balance equations related to the system were established and solve by a simulation program based on an iterative method. The solutions gave the mean temperatures variation according to time and the thermal performance parameters of the system. Theoretical results show the air heater can reach maximum temperatures of $87^{\circ} \mathrm{C}$, $114^{\circ} \mathrm{C}$ and $67^{\circ} \mathrm{C}$ for the cover, the absorber and the outlet air respectively. It was found that experimental and simulated results firmly agree for hours before solar noon. For hours beyond solar noon, a significant difference is noted between theory and experiment, and the experimental values are always higher. This deviation in the afternoon was attributed to the neglecting heat capacity effects in the model. Hence, the theoretical mean value of the removal factor FR and the efficiency factor $F$ ' were 0.4 and 0.33 , whereas the values deduced from experiments are respectively 0.79 and 0.63 . These theoretical and experimental results show that the model of quasi-steady state must be modeled in such a way that it takes into account the heat capacity effects of the solar heater components.

\section{REFERENCES}

Hammou, A., Brunet, S., Le Palec, G and Daguenet, M., 1988. Etude Théorique d'un Absorbeur Poreux. Revue Générale de Thermique; 324: 661-666.

Ong, K. S., 1995. Thermal performance of solar air heaters: Mathematical model and solution procedure. Solar energy; 55, (2): 93-109.

Mohamad, A. A., 1997. High efficiency solar air Heater. Solar Energy; 60, (2): 71-76.

Ekechukwu, O. V and Norton, B., 1999. Review of SolarEnergy Drying Systems III: Low Temperature Air Heating Solar Collectors for Crop Drying applications. Energy Conversion and Management. 40:657-667.

Koyuncu, T., 2006. Performance of various design of solar air heaters for crop drying applications. Renewable Energy; 31:1073-1088.

Aboul-Enein, S., El-Sebaii, A. A., Ramadan, M. R. I and El-Gohary, H. G., 2000. Parametric study of a solar air heater with and without thermal storage for solar drying applications. Renew Energy; 21:505-522.

Abu-Hamdeh, N. H., 2003. Simulation study of solar air heater. Solar Energy; 74:309-317.

Dissa, A. O., Ouoba, S., Bathiebo, D and Koulidiati, J., 2016. A study of a solar air collector with a mixed "porous" and "non-porous" composite absorber. Solar Energy; 129:156-174.

Erbs, D. G., Klein, S. A and Beckman, W. A., 1983. Estimation of degree-days and ambient temperature data from monthly average temperatures. ASHRAE Journal; 25, (6): 60-65.

Swinbank, W. C., 1963. Long-Wave Radiation From Clear Skies. Q. J. R. Meteorol. SOC.; 89:339.

McAdams, W. H., 1954. Heat Transmission. 3rd ed., Mc Graw-Hill, New York;

Hollands, K. G. T., Unny, T. E., Raithby, G. R and Konicek, L., 1976. Free convective heat transfer across inclined air layers. Trans. ASME. J. Heat Transfer; 98:189-193.

Achenbach, E., 1995. Heat and flow characteristics of packed beds. Exp. Thermal Fluid Sci.; 10:17-27.

Tan, H. M and Charters, W. S., 1969. Effect of thermal entrance region on turbulent forced-convective heat transfer for an asymmetrically heated 
rectangular duct with uniform heat flux. Solar Energy; 12: 513-516.

Jain D, Jain, R. K., 2004. Performance evaluation of an inclined multi-pass solar air heater with in-built thermal storage on deep-bed drying application. Journal of Food Engineering; 65:497-509.

Chemkhi, S., Zagrouba, F and Bellagi, A., 2004. Drying of agricultural crops by solar energy. Desalination; 168:101-109.

Goyal, R. K and Tiwari, G. N., 1997. Parametric study of a reverse flat plate absorber cabinet dyer: a new concept. Solar Energy; 60, (1): 41-48.
Madhlopa, A., Jones, S. A., Kalenga, S. J. D., 2002. A solar air heater with composite-absorber systems for food dehydration. Renewable Energy; 27:37-27.

Ayensu, A., 1997. Dehydration of food crops using a solar dryer with convective heat flow. Solar Energy; 59, (4-6):121-6.

Abdelhamid, B., Mustafa, B., Abdellah, B., Bouchra, C. B and Sauveur, B., 1997. Etude numérique d'un séchoir solaire fonctionnant en convection forcée. Rév. Gén. Therm.; 36:837-850. 